\title{
STRATEGI PENGEMBANGAN MANAJEMEN PENGELOLAAN PUSAT KEGIATAN BELAJAR MASYARAKAT (PKBM) DI PROVINSI RIAU
}

\author{
Emma Himayaturohmah \\ Balai Diklat Keagamaan Bandung \\ emmaimayaturohmah@gmail.com
}

Diterima 05 Januari 2017, direvisi 03 Pebruari 2017, diterbitkan 28 Pebruari 2017

\begin{abstract}
Community Learning Center (CLC) is a non-formal education institution that serves as a place and opportunity for the community members to learn. CLC develops as learners' needs, educational regulations, and general society develop. The implementation of learning activities differs from one CLC to another. The quality also varies between one CLC institution and the next. The quality of human resources in CLC contributes to the quality of the CLC. The key human resource that plays a great role in determining the success or failure of CLC is its manager. Managerial ability of CLC managers is one of the key factors of CLC's success. To improve the quality of CLC, the quality of its managers has to be improved first. CLC managers have to possess sufficient knowledge, skills, and capabilities to realize the nine characters of CLC set in the Standard and Operational Procedures of CLC. Nowadays, $C L C$ faces several problems in quality improvement: (1) whether or not the developed learning programs are oriented towards the learners and stakeholders; (2) whether or not all stakeholders of CLC are actively involved in the management and development of CLC; (3) whether or not learning implementation and evaluation been performed as required; it is unlikely that CLC will meet the quality standard set by the community without first having a tool to measure its progress and achievement; (4) whether or not all interested parties have strong commitment to quality improvement; and (5) whether or not the improvement and development efforts in CLC management and learning implementation have been continuous and sustainable. One of the quality improvement efforts in CLC is the development of managerial professionalism. The managers of CLC may implement CLC managerial development strategies, which begin with strategic planning. Managerial development strategies include effective and efficient management of resources and the implementation of skill development and public enrichment approaches.
\end{abstract}

Keywords: Community Learning Center, Quality, Skill, Capability 


\section{Pendahuluan}

Pendidikan nonformal adalah setiap kegiatan pendidikan yang terorganisir, diselenggarakan di luar pendidikan persekolahan, secara tersendiri atau merupakan bagian penting dari suatu kegiatan yang lebih luas dengan maksud memberikan layanan khusus kepada warga belajar di dalam mencapai tujuan belajar (Combs, 1974).

Pendidikan nonformal hadir di tengah masyarakat, bersama-sama dengan pendidikan formal, untuk memastikan tujuan pendidikan pendidikan nasional tercapai.Pendidikan nonformal juga merupakan salah satu pilar penting dalam mencerdaskan Bangsa.Tidak semua lapisan masyarakat mampu menempuh jenjang-jenang pada jalur pendidikan formal.Banyak hambatan dan keterbatasan yang terjadi di masyarakat, terutama masyarakat lapisan bawah. Keterbatasan ekonomi, keterbatasan waktu, persoalan usia, kebutuhan dunia kerja, persoalan jarak, merupakan beberapa alasan penting hadirnya lembaga-lembaga yang dikelola oleh masyarakat dalam lingkup pendidikan nonformal.

Lembaga-lembaga ini memiliki tujuan dan kepedulian dalam menyediakan tempat bagi masyarakat lapisan bawah untuk tetap mendapatkan kesempatan belajar.Di sinilah posisi penting pendidikan nonformal.Salah satu wadah yang menyelenggarakan pendidikan nonformal yang ada di Indonesia adalah Pusat Kegiatan Belajar Masyarakat (PKBM).

Pusat Kegiatan Belajar Masyarakat (PKBM) menurut Standar dan Prosedur Penyelenggaraan PKBM (2012), adalah prakarsa pembelajaran masyarakat yang didirikan dari, oleh dan untuk masyarakat. PKBM adalah suatu institusi yang berbasis masyarakat (Community Based Institution). Artinya, masyarakatlah yang memegang peranan penting dalam pendirian, pengelolaan, proses pembelajaran, pengembangan dan kemajuan sebuah PKBM.

Sebagai institusi yang didirikan oleh, dari dan untuk masyarakat, PKBM memiliki potensi sebagai institusi yang mandiri.Menurut Hiryanto, meskipun awal berdirinya banyak PKBM yang bergantung pada bantuan dan dana block grant dari pemerintah, dalam jangka panjang diharapkan pada sebagian besar PKBM akan tumbuh kemandirian, dalam hal ini peran dominan pemerintah yang selama ini menjadi semakin berkurang dan lebih pada peran fasilitasi akan dapat berjalan seiring dengan kemandirian PKBM. PKBM akan berdiri kokoh atas keswadayaan masyarakat (2009). Menurut Sihombing (1999), tujuan pelembagaan PKBM adalah untuk menggali, menumbuhkan, mengembangkan dan memanfaatkan seluruh potensi yang ada di masyarakat, untuk sebesarbesarnya pemberdayaan masyarakat itu sendiri.

Seperti yang terjadi di sebagian besar PKBMyang ada di Indonesia, PKBM memiliki berbagai permasalahan. Permasalahan yang timbul pun merupakan permasalahan mendasar dari masyarakat berdiri. Keterbatasan sarana prasarana, keterbatasan dana, kurangnya motivasi belajar warga belajar, kurangnya kesadaran warga masyarakat untuk menuntaskan jenjang pendidikan, sulitnya mencari waktu yang pas antara tutor dan warga belajar, terbatasnya ketersediaan tutor yang kompeten, sulitnya mengurus ijin operasional, jauhnya jarak para warga belajar ke tempat belajar, kurangnya kepedulian masyarakat dalam penyelenggaraan kegiatan, sulitnya mencari mitra kerja untuk menjalin kerja sama dalam rangka peningkatan kualitas PKBM, merupakan beberapa permasalahan yang umum terjadi pada PKBM.

Permasalahan-permasalah yang timbul di PKBM, merupakan refleksi nyata kebutuhan keterlibatan semua warga masyarakat serta 
seluruh sumber daya manusia yang peduli terhadap peningkatan kualitas PKBM. Kualitas setiap PKBM berbeda satu dengan yang lainnya.Hal ini merupakan kondisi nyata yang tak bisa dihindarkan. Salah satu faktor penentu kualitas PKBM adalah kualitas pengelola suatu PKBM, selain tutor, yang merupakan agen of changes dari sebuah penyelenggaraan PKBM. Pengelola PKBM akan sangat terkait dengan kualitas layanan yang mereka berikan kepada warga belajar dan tutor, serta penyediaan fasilitas pendukung program-program yang ada di PKBM. Kualitas layanan PKBM akan sangat menentukan keberhasilan program PKBM. Keberadaan Sumber Daya Manusia (SDM) dengan kualifikasi dan Kompetensi memadai, akan memiliki peran penting dalam pengelolaan PKBM serta peningkatan kualitas layanan ideal. Hal ini dipegang oleh pengelola PKBM

Pengelola PKBM merupakan motornya sebuah PKBM.Sehingga, jika ingin meingkatkan mutu PKBM, salah satu caranya adlah dengan meningkatkan kualitas dan kometensi para pengelolanya. Salah satu cara peningkatan mutu tersebut adalah dengan menerapkan strategi pengembangan pengelolaan PKBM. Pada tulisan inilah pembahasan itu diarahkan.

\section{Pendidikan Non-Formal dalam Pemberdayaan Masyarakat}

Pendidikan nonformal memiliki perbedaan dengan pendidikan formal. Sudjana (2010:15) mengidentifikasi beberapa perbedaan pendidikan nonformal dari pendidikan formal, yaitu: derajat ketaatan dan keseragaman yang lebih longgar dibanding pendidikan formal memiliki bentuk dan isi program yang bervariasi, memiliki teknik-teknik yang berbeda dalam mendiagnosis, merencanakan, dan mengevaluasi proses, hasil dan dampak program pendidikan, tujuan pendidikan nonformal tidak seragam, tidak memiliki persyaatan ketat bagi peserta didiknya, tanggung jawab pengelolaan dan pembiayaan pendidikan nonformal dipikul oleh pihak-pihak yang berbeda, serta sistem penyelenggaraannya yang berbeda dari pendidikan formal.

Program-program pendidikan nonformal yangdikembangkan saat ini, merupakan hal yang menarik untuk ditelaah dan dianalisis.Hal ini terkait konsep dan ciri-cirinya yang masih menjadi perdebatan banyak orang. Beberapa kajian dan telaahan yang sering muncul, diantaranya: kondisi tenaga pendidik dan kependidikan nonformal, kondisi sasaran didik, pengembangan kurikulum pembelajaran nonformal, tingkat putus sekolah (drop out) sasaran (warga belajar), model program pembelajaran, model pengembangan materi pembelajaran, standarisasi, lembaga penyelenggaraan pendidikan nonformal, lembaga pengembang model-model pembelajaran, partisipasi masyarakat dan pemerintah, dan lain-lain.

Kontribusi pendidikan nonformal dalam pemberdayaan masyarakat, secara lebih jelas dapat dilihat dari definisi dan hakekat peran pendidikan nonformal itu sendiri. Sudjana secara tegas menjelaskan tugas pendidikan nonformal: (a) membelajarkan warga belajar agar mereka memiliki dan mengembangkan keterampilan, pengetahuan, sikap, nilai-nilai dan aspirasi untuk mengantisipasi pemungkinan perubahan di masa depan, dan (b) membelajarkan warga belajar agar mereka mampu meningkatkan dan memanfaatkan sumber alam guna meningkatkan taraf hidupnya (Sudjana, 1991).

Sejalan dengan pemikiran di atas, Kindervatter (1979:13) menunjukkan secara jelas peran pendidikan nonformal dalam rangka proses pemberdayaan (empowering process), pendidikan nonformal tidak saja berperan dalam mengubahindividu, tetapi juga mengubah kelompok, organisasi dan masyarakat. Pendidikan nonformal sebagai proses 
pemberdayaan mengandung arti luas, yakni mencakup pengetahuan, sikap, keterampilan dan pengembangan kemampuan lainnya ke arah kemandirian hidup. Peran pendidikan nonformal sebagai proses pemberdayaan di dalamnya meliputi peningkatan dan perubahan sumberdaya manusia sehingga mampu membangun masyarakat dan lingkungannya.
Permasalahan, Tantangan dan Potensi PKBM di Provinsi Riau

Provinsi Riau memiliki banyakPKBMyang tersebar di seluruh Kabupaten dan Kota.Data yang diperoleh berdasarkan lembar isian yang disebarkan pada perwakilan PKBM di 12 Kabupaten dan Kota Privinsi Riau, didapatkan data tentang permasalahan, tantangan dan potensi PKBM pada Kabupaten/ Kota adalah sebagaiai berikut:

Tabel 1 Rekapitulasi Data Kelemahan, Keunggulan dan Peluang PKBM Provinsi Riau

\begin{tabular}{|c|c|c|c|c|}
\hline No & $\begin{array}{c}\text { Kabupaten/ } \\
\text { Kota }\end{array}$ & Kelemahan/Masalah & Keunggulan/Potensi & Tantangan \\
\hline 1 & $\begin{array}{l}\text { Kab. } \\
\text { Indragiri } \\
\text { Hilir }\end{array}$ & $\begin{array}{l}\text { - Sarana dan } \\
\text { Prasarana yang } \\
\text { tidak memadai } \\
\text { - Seringnya warga } \\
\text { belajar terlambat } \\
\text { hadir daripada } \\
\text { tutor } \\
\text { - Kurangnya } \\
\text { penerangan di } \\
\text { tempat } \\
\text { pembelajaran } \\
\text { Sulitnya menjalin } \\
\text { hubungan kemitra- } \\
\text { kerjaan } \\
\text { - Lemahnya } \\
\text { pemahaman orang } \\
\text { tua terhadap } \\
\text { PAUD }\end{array}$ & $\begin{array}{l}\text { Program yang } \\
\text { diselenggarakan: } \\
\text { PAUD,KF, A, B, } \\
\text { C, Kursus } \\
\text { Menjahit, TBM, } \\
\text { Life Skill } \\
\text { Mempunyai tutor } \\
\text { yang mudah di atur } \\
\text { - Pengelola bisa } \\
\text { menjabat menjadi } \\
\text { tutor } \\
\text { Pelaksanaan } \\
\text { program life skill } \\
\text { berbasis potensi } \\
\text { daerah } \\
\text { Tutor paket } \\
\text { berprestasi sesuai } \\
\text { jurusan, bahkan } \\
\text { ada yang S2 }\end{array}$ & $\begin{array}{l}\text { Harus mencari } \\
\text { referensi atau } \\
\text { literatur yang } \\
\text { lebih banyak } \\
\text { tentang } \\
\text { pengolahan } \\
\text { hasil potensi } \\
\text { pesisir } \\
\text { Mencari tutor } \\
\text { yang } \\
\text { berpengalaman }\end{array}$ \\
\hline 2 & $\begin{array}{l}\text { Kota } \\
\text { Pekanbaru }\end{array}$ & $\begin{array}{l}\text { - Sarana dan } \\
\text { Prasarana } \\
\text { - Tingkat } \\
\text { kemampuan yang } \\
\text { berbeda } \\
\text { - Animo masyarakat } \\
\text { kurang } \\
\text { - Kehadiran warga } \\
\text { belajar kurang } \\
\text { - Sumber keuangan }\end{array}$ & $\begin{array}{l}\text { - Membatik } \\
\text { - Sablon tata rias } \\
\text { - Pengelola tanaman } \\
\text { hias } \\
\text { - Menjahit } \\
\text { - Tata boga } \\
\text { - hidroponik }\end{array}$ & $\begin{array}{l}\text { - } \\
\text { Dewbentun Donatur } \\
\text { - } \\
\text { Mencari Tim } \\
\text { pengembang }\end{array}$ \\
\hline
\end{tabular}




\begin{tabular}{|c|c|c|c|c|}
\hline 3 & Kota Dumai & $\begin{array}{l}\text { - Gedung belum } \\
\text { memenuhi standar } \\
\text { Minat belajar } \\
\text { masih rendah dan } \\
\text { kehadiran warga } \\
\text { belajar masih } \\
\text { kurang } \\
\text { - Jumlah dana yang } \\
\text { masih terbatas untu } \\
\text { kegiatan } \\
\text { pembelajaran } \\
\text { Masih rendahnya } \\
\text { kesadaran } \\
\text { masyarakat untuk } \\
\text { menutaskan } \\
\text { jenjang pendidkan } \\
\text { Sulitnya dalam } \\
\text { pengurusan ijin } \\
\text { operasional }\end{array}$ & 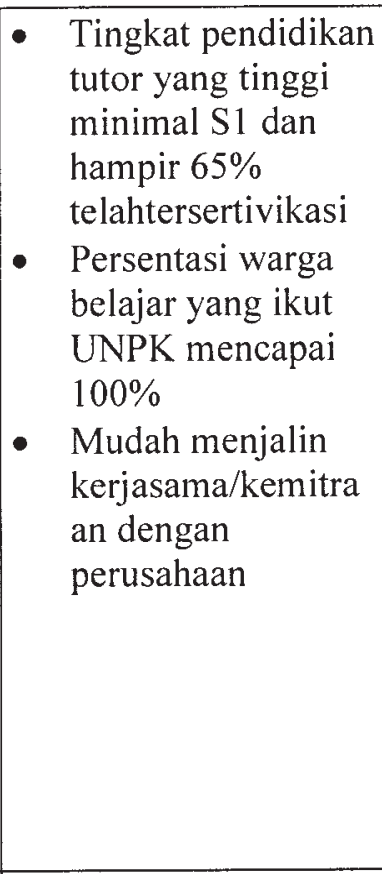 & \begin{tabular}{|l} 
Lebih \\
bersungguh- \\
sungguh dalam \\
mengelola \\
PKBM \\
Kemampuan \\
dalam \\
pembuatan \\
proposal
\end{tabular} \\
\hline 4 & $\begin{array}{l}\text { Kab. } \\
\text { Kepulauan } \\
\text { Meranti }\end{array}$ & $\begin{array}{l}\text { Sulitnya merekrut } \\
\text { warga belajar yang } \\
\text { aktif belajar } \\
\text { seminggu } 3 \text { kali } \\
\text { Pengaturan waktu } \\
\text { belajar bagi warga } \\
\text { belajar } \\
\text { Belum memiliki } \\
\text { gedung sendiri } \\
\text { Menyesuaikan } \\
\text { jadwal belajar } \\
\text { warga belajar } \\
\text { dengan tutor }\end{array}$ & $\begin{array}{l}\text { Paket A, B, dan C, } \\
\text { KF, TBM, PKW } \\
\text { Menjahit } \\
\text { Aktivitas warga } \\
\text { sangat tinggi } \\
\text { Tutor yang } \\
\text { mendatangi warga } \\
\text { belajar } \\
\text { Juara II Tutor KF } \\
\text { Tingkat Provinsi } \\
\text { Tahun 2015 } \\
\text { Juara III tutor KF } \\
\text { tingkat Provinsi } \\
\text { tahun } 2016\end{array}$ & 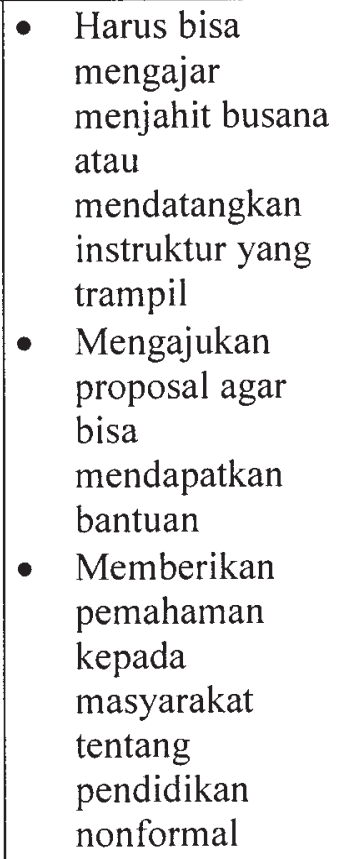 \\
\hline 5 & $\begin{array}{l}\text { Kab. Kuantan } \\
\text { Singingi }\end{array}$ & $\begin{array}{l}\text { Tidak memiliki } \\
\text { fasilitas yang } \\
\text { memadai dalam } \\
\text { penyelenggaraan } \\
\text { Tidak ada atau } \\
\text { tidak tetapnya dana } \\
\text { untuk } \\
\text { penganggaran } \\
\text { program } \\
\text { Belum bisa }\end{array}$ & 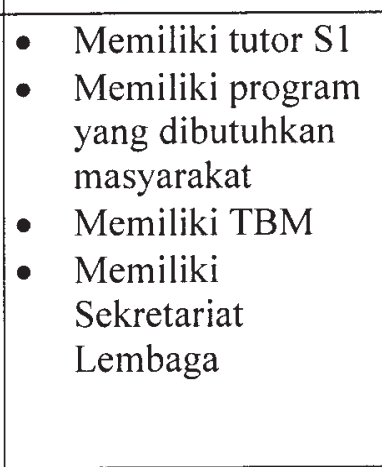 & $\begin{array}{l}\text { - Sulit } \\
\text { mendapatkan } \\
\text { pihak ketiga } \\
\text { untuk menjalin } \\
\text { kerjasama }\end{array}$ \\
\hline
\end{tabular}




\begin{tabular}{|c|c|c|c|c|}
\hline & & $\begin{array}{l}\text { mandiri tanpa } \\
\text { bantuan } \\
\text { pemerintah } \\
\text { Rendahnya tingkat } \\
\text { kehadiran warga } \\
\text { belajar }\end{array}$ & & \\
\hline 6 & $\begin{array}{l}\text { Kab. Rokan } \\
\text { Hulu }\end{array}$ & $\begin{array}{l}\text { Kurangnya minat } \\
\text { belajar warga } \\
\text { belajar } \\
\text { Kurangnya } \\
\text { perhatian } \\
\text { pemerintah daerah } \\
\text { terhadap PKBM } \\
\text { Kurangnya } \\
\text { motivasi orang tua } \\
\text { terhadap anaknya } \\
\text { belajar di PKBM } \\
\text { - Kurangnya sarana } \\
\text { prasarana } \\
\text { - SDM tutor } \\
\end{array}$ & $\begin{array}{l}\text { Menjalin } \\
\text { kerjasama atau } \\
\text { kemitraan dengan } \\
\text { lembaga lain } \\
\text { Pendidikan tutor } \\
\text { minimal S1 dan } \\
\text { memiliki sertivikat } \\
\text { pendidik }\end{array}$ & 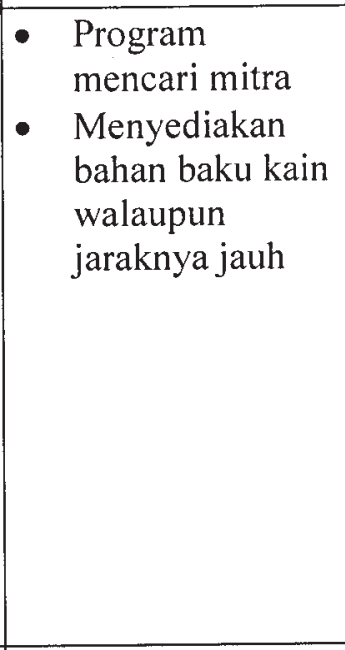 \\
\hline 7 & Kab. Siak & $\begin{array}{l}\text { - } \text { Pendanaan } \\
\text { - Sarana Prasarana } \\
\text { - } \text { SDdung } \\
\text { SDM }\end{array}$ & $\begin{array}{l}\text { - Sudah akreditasi } \\
\text { Konservasi hutan } \\
\text { mangroove } \\
\text { Ekowisata } \\
\text { mangroove } \\
\text { - Vokasi (membuka } \\
\text { bengkel sepeda } \\
\text { motor binaan } \\
\text { Yamaha) } \\
\text { - Program Proklin } \\
\text { tingkat nasional } \\
\text { (KLH) } \\
\text { Pariwisata } \\
\text { Kampung } \\
\text { Mempura } \\
\end{array}$ & $\begin{array}{l}\text { Harus membuat } \\
\text { program kerja } \\
\text { yang baik } \\
\text { Melakukan } \\
\text { evaluasi }\end{array}$ \\
\hline 8 & Kab. Kampar & $\begin{array}{l}\text { Program KF } \\
\text { (menjahit): } \\
\text { rendahnya minat } \\
\text { belajar warga } \\
\text { sehingga } \\
\text { timbulnya rasa } \\
\text { pesimis terhadap } \\
\text { tercapainya tujuan } \\
\text { kegiatan } \\
\end{array}$ & $\begin{array}{l}\text { - } \\
\text { Kerpras lengkapama dengan } \\
\text { tutor terjalin } \\
\text { dengan baik } \\
\text { - Tingginya } \\
\text { pengabdian dalam } \\
\text { PBM }\end{array}$ & $\begin{array}{l}\text { Bagaimana } \\
\text { meyakinkan } \\
\text { warga belajar } \\
\text { bahwa kegiatan } \\
\text { yang dimaksud } \\
\text { mempunyai } \\
\text { prospek yang } \\
\text { menguntungkan }\end{array}$ \\
\hline 9 & $\begin{array}{l}\text { Kab. } \\
\text { Indragiri } \\
\text { Hulu }\end{array}$ & 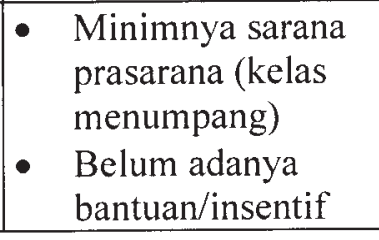 & $\begin{array}{ll}\text { Program yang } \\
\text { dilaksanaan } \\
\text { Kesetaraan, TBM, } \\
\text { Paket A, B, C } \\
\text { - Prestasi: Pengelola } \\
\end{array}$ & $\begin{array}{l}\text { Mampu menjalin } \\
\text { kerjasama dengan } \\
\text { perusahaan yang } \\
\text { dimaksud }\end{array}$ \\
\hline
\end{tabular}

Strategi Pengembangan Manajemen Pengelolaan Pusat Kegiatan Beajar Masyarat (PKBM) di Provinsi Riau | Emma Himayaturohmah 


\begin{tabular}{|c|c|c|c|c|}
\hline & & $\begin{array}{l}\text { unuk pengelola } \\
\text { PKBM seperti } \\
\text { dengan sekoah lain } \\
\text { Dana yang } \\
\text { dikerjakan tidak } \\
\text { berkelanjutan } \\
\text { Kehadiran warga } \\
\text { belajar masih } \\
\text { minim merupakan } \\
\text { masalah yang } \\
\text { sering ditemui } \\
\text { Masalah } \\
\text { yanberhubungan } \\
\text { dengan } \\
\text { pengelolaan: } \\
\text { penerapan SPP, } \\
\text { begitu tagihan } \\
\text { warga belajar tidak } \\
\text { mampu } \\
\end{array}$ & \begin{tabular}{|l} 
TBM Juara I \\
Tigkat Provinsi \\
tahun 2013, \\
Pengelola TBM \\
juara 2 Tingkat \\
Provinsi 2011 \\
Keunggulan \\
prestasi tutor: \\
Tutor dari sekolah \\
formal \\
- Tutor lulusan S1 \\
- Keunggulan \\
PKBM: Sarana \\
prasarana \\
Gedung \\
menumpang di \\
PKBM sendiri
\end{tabular} & \\
\hline 10 & $\begin{array}{l}\text { Kab. } \\
\text { Pelalawan }\end{array}$ & $\begin{array}{l}\text { Fasilitas KBM } \\
\text { yang belum } \\
\text { maksimal } \\
\text { Warga belajar } \\
\text { banyak yang } \\
\text { kurang aktif } \\
\text { mengikuti KBM } \\
\text { Tutorbelum } \\
\text { terpenuhi untuk } \\
\text { daerah terpencil } \\
\text { - Susah melengkapi } \\
\text { berkas akreditasi } \\
\text { Gedung belajar } \\
\text { dan kantor masih } \\
\text { pinjam pakai } \\
\text { - Sulitnya sosialisasi } \\
\text { kepada masyarakat } \\
\text { tentang PKBM } \\
\text { Masalah } \\
\text { pengelolaan dana } \\
\end{array}$ & $\begin{array}{l}\text { Program: PAUD, } \\
\text { Paket A, B, C, KF, } \\
\text { TBM } \\
\text { Prestasi: Program } \\
\text { PAUD juara II Tk } \\
\text { Provnsi Provinsi } \\
2015 \\
\text { - Tutorberprestasi } \\
\text { - Menyelenggarakan } \\
\text { semua kgiatan } \\
\text { pembelajaran }\end{array}$ & $\begin{array}{l}\text { SDM yang } \\
\text { belum } \\
\text { kompeten } \\
\text { Menyamakan } \\
\text { misi dengan } \\
\text { organisasi mitra }\end{array}$ \\
\hline 11 & $\begin{array}{l}\text { Kab. } \\
\text { Bengkalis }\end{array}$ & $\begin{array}{l}\text { Warga kurang } \\
\text { antusias dalam } \\
\text { mengikuti proses } \\
\text { belajar }\end{array}$ & 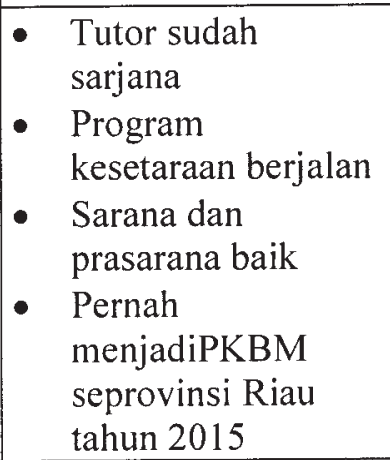 & \begin{tabular}{|l} 
Warga belajar \\
usia muda lebih \\
susah diatur \\
Menjadi mitra \\
dengan \\
perguruan \\
tinggi dan DPR \\
dan dinas terkait
\end{tabular} \\
\hline
\end{tabular}




\begin{tabular}{|c|c|c|c|c|}
\hline 12 & $\begin{array}{l}\text { Kab. Rokan } \\
\text { Hilir }\end{array}$ & $\begin{array}{l}\text { Warga belajar } \\
\text { yang berbeda } \\
\text { Letak geografis } \\
\text { yang berjauhan } \\
\text { Warga belajar } \\
\text { kurang serius dan } \\
\text { kehadiran kurang } \\
\text { dari } 100 \text { persen, } \\
\text { kurang disiplin, } \\
\text { tidak tepat waktu } \\
\text { dan rendahnya } \\
\text { kesadaran untuk } \\
\text { belajar } \\
\text { Administrasi: } \\
\text { keuangan, } \\
\text { program, } \\
\text { media/sarana } \\
\text { belajar }\end{array}$ & 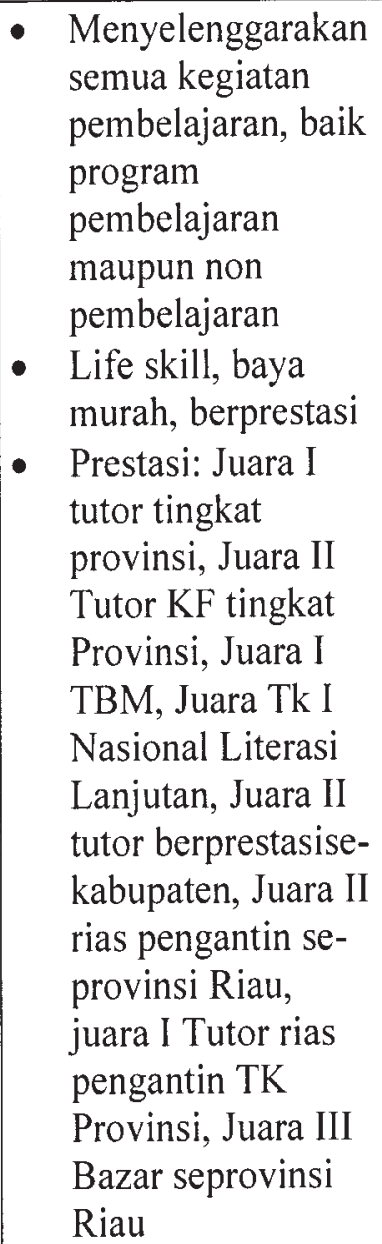 & $\begin{array}{l}\text { - Membuat hasil } \\
\text { usaha mandiri } \\
\text { Bekerja sama } \\
\text { dengan } \\
\text { masyarakat dan } \\
\text { intansi terkait } \\
\text { - Meningkatkan } \\
\text { kemampuan } \\
\text { membuat } \\
\text { proposal untuk } \\
\text { pengajuan dana } \\
\text { kepada calon } \\
\text { mitra }\end{array}$ \\
\hline
\end{tabular}

Sumber: Hasil Lembar Kerja Peserta Pelatihan.

\section{Strategi Pengelolaan PKBM}

Pengaruh perubahan masyarakat yang sangat cepat menuntut konsep pengelolaan PKBM untuk membuka diri terhadap tuntutan perubahan dan berupaya menyusun strategi yang selaras dengan perubahan masyarakat.

Strategi yang dijalankan oleh seluruh komponen PKBM (komunitas binaan/sasaran, peserta didik, pendidik/tutor/instruktur/ narasumber, penyelenggara dan pengelola dan mitra PKBM) harus selaras dan sejalan. Hal ini untuk memastikan tujuan dan sasaran yang sama.

Salah satu komponen PKBM, yang memegang peranan penting dalam pengembangan PKBM adalah pengelola PKBM. Seperti yang telah ditetapkan dalam Standar dan prosedur penyelenggaraan PKBM, pengelola PKBM harus memenuhi persyaratan sebagai berikut: memiliki kepedulian yang tinggi terhadap pendidikan dan pemberdayaan masyarakat, memiliki dedikasi yang tinggi pada pendidikan dan bertanggungjawab, memiliki jaringan yang luas, memiliki kemampuan teknis di bidang pendidikan nonformal dan pemberdayaan masyarakat.

Pengelola PKBM akan mampu menyusun strategi yang tepat, terutama dalam rangka mengatasi setiap perubahan yang terjadi, jika 
didukungfungsi manajerial yang tangguh. Salah satu bidang fungsional strategisyang harus menjadi perhatian pengelola adalah manajemen sumber daya manusia.

Jika PKBM ingin berkembang menjadi PKBM yang profesional dan berorientasi ke depan, maka berikut ini dikembangkan strategistrategi sumber daya manusia yang dapat menggerakkan PKBM menjadi lebih profesional: strategi rekruitment dan seleksi, strategi perencanaan sumberdaya manusia, strategi pelatihan dan pengembangan, strategi penilaian kinerja, strategi kompensasi dan strategi manajemen-staf/karyawan. (Kamil, 2009).

Menerapkan konsep strategi pengelolaan PKBM dimulai dari melakukan perencanaan yang komprehensif. Perencanaan program kegiatan yang komprehensif, yaitu perencanaan program yang mampu mengantisipasi kebutuhan yang bervariasi dan luas, untuk jangka panjang, dengan menggunakan sumber-sumber yang tersedia dan paling baik untuk mencapai tujuantujuan program.

Pengelola PKBM akan mampu mengelola sumber-sumber yang dibutuhkan apabila didukung oleh kemampuan menyusun strategi yang ampuh dalam menjalankan fungsi manajerial yang dimilikinya. Tiga hal penting yang perlu dimiliki oleh seorang pengelola PKBM dalam rangka mengelola sumbersumber yang tersedia secara efektif dan efisien adalah pengetahuan, kemampuan dan keterampilan memahami perilaku manusia dan perilaku organisasi.

Beberapa strategi dasar yang dapat dikembangkan dalam pengelolan sumbersumber agar efektif dan efisien (Kamil, 2009), yaitu: (a) berikan pemahaman melalui pelatihan kecil kepada warga belajar, tutor, fasilitator, masyarakat tentang program yang akan dikembangkan dan menjadi tanggungjawabnya; (b) berikan kepercayaan penuh kepada pengelola program, mulai dari perencanaan, pelaksaaan program sampai padapengontrolan dan evaluasi; (c) kembangkan kerjasama dan kemitraan yang erat dan terbuka dengan pihakpihak tertentu atau masyarakat (tokoh masyarakat) yang potensial dapat dilibatkan dalam pengembangan dan pengendalian program. Jika memungkinkan dengan pemerintah, pihak swasta dan sponsor lainnya; (d) gunakan barang, bahan, alat yang sesuai kebutuhan pengembangan program; (e) berikan kesempatan kepada pengelola program atau masyarakat untuk membuat keputusan dan mempertanggungjawabkan keputusannya; (f) gunakan tim keuangan dari luar untuk mengontrol pembiayaan agar mandiri; (g) maksimalkan sumberdaya yang ada di PKBM dalam pengembangan dan pengendalian program; (h) kembangkan materi pembelajaran yang lebih tematik, lokal, sehingga sesuai dengan kondisi lingkungan masyarakat dan kebutuhan warga belajar; (i) partisipasi warga belajar.

Manajemen program PKBM dalam pengembangannya, bisa mengacu pada manajemen yang dikembangkan pada konsep manajemen pendidikan luar sekolah.Karena, PKBM merupakan bagian dari implementasi pendidikan luar sekolah (Penjelasan Pasal 26 ayat 3 UU Sisdiknas No. 20/2003).Manajemen pendidikan luar sekolah adalah upaya menerapkan fungsi-fungsi pengelolaan baik untuk setiap kegiatan yang berkaitan dengan kelembagaan pendidikan luar sekolah maupun untuk satuan penidikan luar sekolah.Kegiatan yang berkaitan dengan kelembagaan pendidikan luar sekolah mencakup upaya birokratis untuk melaksanakan, membina dan mengembangkan isntitusi pendidikan luar sekolah (Sudjana, 1991).

Secara spesifik, Sudjana menyatakan bahwa komponen dasar dari sebuah manajemen pendidikanluar sekolah meliputi fungsi-fungsi: perencanaan, pengorganisasian, penggerakkan, pembinaan, penilaian dan pengembangan.

Dari gambar tersebut dapat dijelaskan 
bahwa program PKBM dimulai dari perencanaan.Perencanaan program PKBM sanat berkaitan dengan penyusunan tujuan dan rangkaian kegiatan untuk mencapai tujuan lembaga penyelenggara program. Perencanaan terkaitan dengan penyusunan pola, rangkaian dan proses kegiatan yang akan dilakukan untuk mencapai tujuan. Setelah perencanaan dilakukan, maka pengoganisasian mutlak dilakukan. Pengorganisasian adalah kegiatan mengidentifikasi dan memadukan sumbersumber yang diperlkan ke dalam kegiatan yang akan dilakukan dalam mecapai tujuan yang telah ditetapkan. Sumber-sumber itu meliputi: tenaga manusia, fasilitas, alat-alat, dan biaya. Jelasnya, pengorganisasian adalah upaya melibatkan semua sumber manusia dan non-manusia ke dalam kegiatan yang terpadu, untuk mencapai tujuan dan lebaga atau organisasi penyelenggaran program PKBM. Selama perencanaan dan pengorganisasian dilakukan, penggerakkan memainkan peranan yang cukup signifikan.Fungsi penggerakkan adalah mewujudkan tingkat penampilan dan partisipasi yang tinggi dari setiap pelaksana yang terlibat dalam kegiatan untuk mencapai tujuan yang telah ditetapkan. Penggerakkan dapat dilakukan dengan upaya menumbuhkan dan mengembangkan kemampuan, semangat, percaya diri dan partisipasi atau dengan menghargai nilai-nilai kemanusiaan setiap pihak yang terlibat dalam proses manajemen.

\section{Kesimpulan}

Peningkatan mutu Pusat Kegiatan Belajar Mayarakat (PKBM), salah satunya dengan melakukan pengembangan strategi pengelolaan PKBM.Konsep Strategi pengelolaan PKBM harus dimulai dengan perencanaan yang komprehensif.Ada dua strategi dasar yang dapat diterapkan oleh para pengelola PKBM dalam pengembangan strategi pengelolaan PKBM.Strategi itu adalah pengelolaan sumber- sumber secara efektif dan efisien serta penerapan pendekatan pengembangan kemampuan dan pemberdayaan masyarakat.Jika menggunakan strategi mengelola sumber-sumber yang tersedia secara efektif dan efisien, maka ada 3 hal yang harus dimiliki oleh seorang pengelola PKBM, yaitu: pengetahuan, kemampuan dan keterampilan memahami perilaku manusia dan perilaku organisasi. Bila menggunakan pendekatan pengembangan kemampuan dan pemberdayaan masyarakat, pelaksanaannya harus mempertimbangkan pendekatan individual, organisasi dan jaringan, serta memberdayakan kelompok belajar.Pengelola PKBM bebas menentukan strategi mana yang akan dilaksanakan. Pertimbangan yang terpening adalah kesesuaia program-program yang diselenggarakan dengan strategi yang diterapan.

Pada tataran praktis, pengelola PKBM harus mengoptimalkan fungsi-fungsi manajemen Pendidikan Luar Sekolah pada Pusat Kegiatan Belajar yang mereka kelola. Fungsi-fungsi tesebut adalah: perencanaan, pengorganisasian, penggerakkan, pembinaan, penilaian dan pengembangan. Jika fungsi-fungsi tersebut dilaksanakan dengan baik, maka pengembangan strategi pengelolaan PKBM berjalan dengan baik.

\section{DAFTAR PUSTAKA}

Combs, PWith Ahmed, M. (1974).Attacking Rural Poperty, Baltimore: The John Hopkins University Press. How Non Formal Education can help, Baltimore: John Hopkins University Press

Direktorat Pembinaan Pendidikan Masyarakat Direktorat Jenderal Pendidikan Anak Usia Dini Nonformal Dan Informal Kementerian Pendidikan Dan Kebudayaan. (2012) Standar Dan Prosedur Penyeleng- 
garaan Pusat Kegiatan Belajar Masyarakat (PKBM)

Hiryanto. (2009). Strategi Pengelolaan dan Pengembangan Pusat Kegiatan Belajar Masyarakat (PKBM). Makalah pada Pelatihan Tenaga Pendidik PKBM

Kamil, M. (2009) Pendidikan Nonformal, Pengembangan Melalui Pusat Kegiatan Belajar Masyarakat (Sebuah Pembelajaran dari Jepang). Bandung: Alfabeta

Kindervatter, S. (1979) Non-Formal Education, as an Empowering Process, Anhest, Mass: Center for International Education
Sihombing, Umberto. (1999). Pendidikan Luar Sekolah, Kini dan Masa Depan: Konsep, Kiat dan Pelaksanaan. Jakarta: PD Mahkota.

Sudjana, (1991) Pendidikan Luar Sekolah, Wawasan, Sejarah, Perkembangan Falsafah dan TeoriPendukung. Bandung: Nusantara Press.

Sudjana, (2010) Pendidikan Nonformal, Wawasan Sejarah Perkembangan Filsafat Teori Pendukung Asas, Bandung: Falah Production.

Suryono, Y (2007). Peningkatan Kemampuan Pusat Kegiatan Belajar Masyarakat (PKBM). Yogyakarta: UNY Press. 